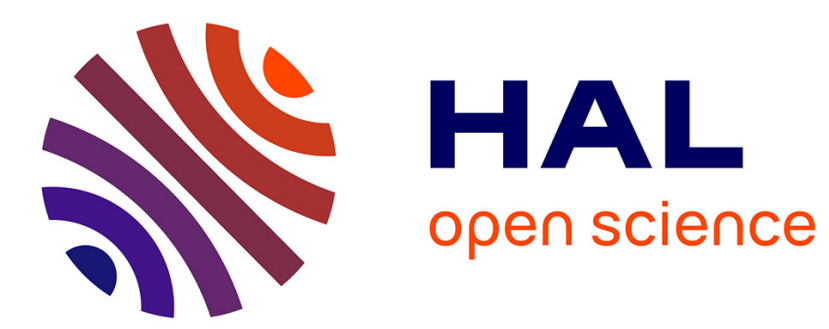

\title{
Langues de France des Outre-mer
}

Isabelle Léglise

\section{To cite this version:}

Isabelle Léglise. Langues de France des Outre-mer. Langage et Société, 2021, Dictionnaire de la sociolinguistique, Hors-série, pp.197-200. hal-03354255

\section{HAL Id: hal-03354255 \\ https://hal.science/hal-03354255}

Submitted on 24 Sep 2021

HAL is a multi-disciplinary open access archive for the deposit and dissemination of scientific research documents, whether they are published or not. The documents may come from teaching and research institutions in France or abroad, or from public or private research centers.
L'archive ouverte pluridisciplinaire HAL, est destinée au dépôt et à la diffusion de documents scientifiques de niveau recherche, publiés ou non, émanant des établissements d'enseignement et de recherche français ou étrangers, des laboratoires publics ou privés. 
Isabelle Léglise, 2021, « Langues de France des Outre-mer », Langage et société, Hors-série, 197-200.

Langues de France des Outre-mer

Léglise Isabelle. CNRS

isabelle.leglise@cnrs.fr

Sur les 75 langues reconnues comme «langues de France », 54 sont issues de 1'Outre-mer. Le site du Ministère de la Culture en donne la définition suivante : «On entend par langues de France les langues régionales ou minoritaires parlées par des citoyens français sur le territoire de la République depuis assez longtemps pour faire partie du patrimoine culturel national, et ne sont langue officielle d'aucun État ». A la suite de consultations avec des linguistes spécialistes des différents territoires, ces langues ont d'abord été identifiées dans le rapport Cerquiglini remis en 1999 au Ministre de l'Éducation Nationale et à la Ministre de la Culture avant de faire l'objet de différentes publications (Cerquiglini 2003). Il s'agissait alors de recenser les langues susceptibles de remplir les critères de la Charte européenne des Langues Régionales et Minoritaires, signée mais finalement jamais ratifiée par la France, visant à promouvoir ces langues et leur emploi.

La plupart des 54 langues ultramarines sont parlées par les peuples autochtones de ces territoires, c'est le cas des

- 9 langues polynésiennes et 28 langues kanak en Océanie,

- 6 langues amérindiennes en Guyane,

- du shimaoré et kibushi à Mayotte.

S'ajoutent 8 langues créoles, issues de l'esclavage et des contacts entre colons, populations déplacées et populations locales, qui se sont développées au XVIIIe s :

- 4 à base lexicale française (en Guadeloupe, Martinique, Guyane et à la Réunion),

- 4 à base anglaise ou anglo-portugaise parlées en Guyane par des descendants de Marrons.

Enfin, le hmong, parlé en Guyane par un petit groupe de réfugiés laotiens naturalisés au milieu des années 1970, a été ajouté comme « cas limite » et fait état d'exception.

Bien que déjà riche, cette liste occulte un grand nombre de langues présentes sur ces territoires et issues de mobilités plus récentes comme, par exemple, le hakka et le punti en Polynésie française, le bislama en Nouvelle-Calédonie ou encore le portugais du Brésil et le créole haïtien parlés par des parties importantes de la population guyanaise. Elle ne traite pas des langues de France en dehors de leur espace d'origine, comme le wallisien et le futunien en Nouvelle-Calédonie ou les créoles antillais en Guyane. Ainsi, alors qu'on dénombre une trentaine de langues parlées en Guyane, par des citoyens ayant la nationalité française, la liste n'en mentionne que dix. Enfin, elle reflète une partie de l'état des connaissances à un moment donné. Elle ne mentionne pas, par exemple, le créole à base anglaise de Saint-Martin, collectivité d'outre-mer depuis 2007.

La situation sociolinguistique et les dispositifs statutaires des douze territoires ultramarins sont particuliers (Lemercier et alii 2014) mais les langues qui y sont parlées partagent, pour leur grande majorité, les caractéristiques d'être des langues de communication quotidienne et 
d'être transmises en famille. Parfois, comme à la Réunion ou aux Antilles, créole et français sont entremêlés dès le plus jeune âge. Parfois, comme en Guyane, à Wallis ou à Mayotte, une majorité de jeunes enfants ne parlent pas français avant d'être scolarisés. Par ailleurs, dans telle commune de Guyane, on peut très bien échanger et travailler en s'exprimant uniquement dans un créole à base anglaise, ou en portugais du Brésil par exemple, sans avoir besoin du français. Ainsi, si la population est souvent plurilingue, elle peut avoir un degré de connaissance du français assez limité. Un problème important d'accès aux droits de la population en découle : accès à l'éducation, à la santé, à la justice et aux services publics en général qui s'adressent généralement en français à leurs administrés... pas forcément francophones. Dans le domaine de l'éducation, l'absence de prise en compte des langues parlées par les élèves a été identifiée comme l'une des raisons majeures de l'échec scolaire voire d'un taux d'illettrisme important - en Outre-mer.

Ceci distingue très fortement la situation des langues régionales dans l'hexagone de celle en Outre-mer. Leur reconnaissance comme « langues de France » puis leur mention dans le code de l'éducation leur a ouvert une relative «tolérance constitutionnelle », par exemple un enseignement possible pour autant qu'il soit facultatif comme en Polynésie ou en Nouvelle Calédonie depuis 2004 (Vernaudon et alii 2014) - mais, vingt ans après l'apparition de la catégorie « langues de France », il apparaît que cela ne leur a pas ouvert un certain nombre de droits réservés aux langues régionales (Bertile 2020). La loi Deixonne, d'abord réservée à certaines langues régionales de l'hexagone, avait déjà été étendue à certaines langues d'Outremer : au tahitien (en 1981), à 4 langues kanak (en 1992), et aux langues créoles (en 2002). La circulaire Savary avait également permis aux créoles d'être enseignés comme langues et cultures régionales à partir de 1982. Depuis, un certain nombre de dispositifs expérimentaux ont été mis en place. Des Intervenants en Langues Maternelles existent dans 9 langues de Guyane depuis 1998, des classes bilingues français-créole guyanais à parité horaire depuis 2008, de premières classes bilingues français-kali'na et français-nenge depuis 2017 (Alby et Léglise 2016). Des approches pédagogiques spécifiques sont désormais possibles dans les académies d'Outre-mer «dans l'enseignement de l'expression orale ou écrite et de la lecture au profit des élèves issus de milieux principalement créolophone ou amérindien » (Code de l'éducation, L321-4).

Si l'Education nationale a été accusée de ne pas mettre en place de politiques linguistiques éducatives ambitieuses allant vers un véritable enseignement plurilingue qui s'appuierait sur les ressources langagières des élèves ultramarins, c'est paradoxalement l'un des domaines où les langues locales ont actuellement une place relative. Dans les domaines de la santé ou de la justice, on continue à se demander quel accès aux services publics est possible pour des citoyens non francophones (Léglise 2011). Récemment, un certain nombre de rapports officiels préconisent une plus grande reconnaissances et utilisation des langues de l'Outremer ; les Etats Généraux du Multilinguisme dans les Outre-mer ont abouti à la déclaration de

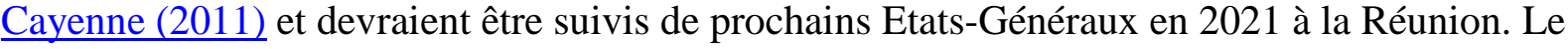
rapport de la commission nationale consultative des droits de l'Homme (2017) recommande notamment de traduire et diffuser les informations juridiques dans les médias locaux « dans le respect de la tradition orale et du multilinguisme propres aux territoires » ultramarins. Pour une meilleure cohésion sociale, le Conseil économique et social (2019) recommande enfin l'utilisation des langues de l'Outre-mer non seulement dans l'éducation où " chaque enfant doit avoir la possibilité d'apprendre à lire et à écrire dans sa langue maternelle » mais également, dans les services publics, pour l'accès à la santé, l'éducation, la police, au droit et à la Justice. 
Isabelle Léglise, 2021, " Langues de France des Outre-mer », Langage et société, Hors-série, 197-200.

\section{REFERENCES}

Alby S. et I. Léglise (2016) «L'éducation bilingue dans le contexte multilingue guyanais: dispositifs cloisonnants et pratiques pédagogiques innovantes ». Dans L'éducation bilingue en France: politiques linguistiques, modèles et pratiques, Hélot C. et Erfurt J. (dir), 66- 86. Limoges, Lambert Lucas. En ligne: https://hal.archivesouvertes.fr/hal-01426303/document

Bertile V. (2020) «Les langues d'Outre-mer: des langues de France? » Glottopol 34: 118- 31.

Cerquiglini B. (dir) (2003) Les langues de France. Paris, PUF.

Léglise I. (2011) «Quel accès aux soins et aux services publics pour des citoyens non francophones?»Culture et Recherche, $\mathrm{n}^{\circ}$ 125: 10- 11.

Lemercier É., V. Muni Toke, et É. Palomarès (2014) «Les Outre-mer français ». Terrains \& travaux, $\mathrm{n}^{\mathrm{o}} 24$ (octobre): 5- 38.

Vernaudon, J., O. Renault-Lescure, et I. Léglise (2014) «Les langues de Nouvelle Calédonie, Polynésie et Guyane». Dans Apprendre plusieurs langues, plusieurs langues pour apprendre: l'école plurilingue en Outre-mer, Nocus O., J. Vernaudon, et M. Paia (dir), 101- 26. Rennes, Presses Universitaires de Rennes.

Renvois : Droit linguistique; Education plurilingue; Langue ; Langue régionale ; Politique linguistique 